\title{
IMAGINARIOS DE MODERNIZACIÓN LATINOAMERICANOS: GLORIFICACIÓN TECNOLÓGICA, UTOPÍA E INVENCIÓN EN LAS ARTES VISUALES Y LA LITERATURA DE VANGUARDIA
}

\author{
Latin American imaginaries of modernization: technological glorification, \\ utopia and invention in the visual arts and avant-garde literature
}

Jazmín Adler ${ }^{1}$

\begin{abstract}
RESUMEN
El presente artículo analiza la construcción de los imaginarios de modernización latinoamericanos configurados en torno a los desarrollos técnicos advenidos a principios del siglo XX, así como el modo en que cierta glorificación tecnológica impactó en las artes visuales y la literatura de vanguardia. Luego de rastrear la atracción ejercida por la técnica en algunos movimientos de vanguardia europeos, el trabajo sostiene que, en nuestra región, diversas obras cuestionaron la exaltación acrítica de la máquina y propusieron, en cambio, lenguajes vernáculos basados en las nociones de utopía e invención. El artículo concluye que glorificación técnica, utopía e invención son conceptos que no solo permiten articular las diferentes concepciones poéticas, políticas y tecno-científicas que poco a poco fueron gestándose en la escena local, sino que también posibilitan tender puentes entre las obras de las primeras vanguardias y las emergencias del arte contemporáneo.
\end{abstract}

Palabras clave: Artes visuales, imaginarios de modernización, literatura, tecnología, vanguardias.

\begin{abstract}
This article addresses the construction of Latin American imaginaries of modernization in relation to the technical developments that have arisen by the beginning of the $20^{\text {th }}$ century. It also studies the way in which the glorification of technology produced a strong impact on the avant-garde in the visual arts and literature. After analyzing the attraction of European avant-gardes movements towards Technique, this essay argues that in our region several works of art questioned the uncritical exaltation of the machine. Instead, they proposed local artistic languages based on the notions of utopia and invention. The article concludes by stating that the glorification of technology, utopia and invention are concepts that not only enable to articulate different poetic, political and techno-scientific conceptions that have gradually appeared on the local scene, but they also contribute to build bridges between the artworks of the first avant-gardes and the emergencies of contemporary art.
\end{abstract}

Key Words: Avant-gardes, imaginaries of modernization, literature, technology, visual arts.

\section{Primeras consideraciones sobre el concepto de imaginario}

Deconstruir las constelaciones de sueños, ilusiones, mitos y fantasías que instauran imaginarios individuales y colectivos no resulta una tarea sencilla. Para Beatriz Sarlo (1992, p. 11), el problema suscitado a la hora de estudiar las dimensiones simbólicas que permiten recomponer lo imaginado radica en la dificultad para encontrar las fuentes en las cuales

\footnotetext{
${ }^{1}$ Universidad de Buenos Aires. Universidad Nacional de Tres de Febrero. Doctora en Teoría Comparada de las Artes y licenciada en Artes. Docente e investigadora. Argentina.

Correo eletrónico: jazminadler@gmail.com
} 
dichos idearios son representados -los soportes en que aquellos contenidos de significancia cobran cuerpo, diría José Luis Brea (2002)-, así como identificar con exactitud su repercusión en las actitudes de la época.

La noción de imaginario se encuentra emparentada con el concepto de imagen, pero también remite al de imaginación, es decir, adquiere un matiz inventivo que escapa de lo meramente reproductivo. Este punto es recordado por Carlos Altamirano (1990) cuando, en su artículo dedicado a las relaciones entre lo imaginario y el análisis socio-histórico, plantea que la jerarquización del aspecto imaginario de una representación supone el distanciamiento del reflejo de lo real. Precisamente, la hipótesis de Cornelius Castoriadis (1975) sobre el imaginario social se aparta de la concepción marxista de las ideas como reflejo de las relaciones de producción. Sugiere que el imaginario social instituyente crea significaciones imaginarias que construyen lo histórico-social y se encarnan en instituciones. Ciertos significados son naturalizados en tanto devienen en imaginario instituido. Estas significaciones representan el mundo que fundan, tanto la sociedad en sí misma como el lugar que aquella ocupa en el mundo creado (Castoriadis, 1975, p. 9). Ahora bien, la creación no se reduce al aspecto intelectual, sino que compromete un nivel afectivo. Si la sociedad existente es reemplazada por una nueva cultura, el proceso de transformación económico, social y político "irá de la mano de un trastrocamiento de las significaciones establecidas, de los marcos de racionalidad, de la ciencia de los últimos siglos y de la tecnología que le es homóloga" (Castoriadis, 2004, p. 17).

Bronislaw Baczko (1991) también afirmó que las representaciones de la realidad, históricamente formadas por las sociedades con el objetivo de auto-proporcionarse una identidad, no deben ser leídas como meros reflejos de aquella. Partiendo de materiales tomados del continuum simbólico, los grupos sociales elaboran "ideas-imágenes" -término alusivo de manera simultánea a los conceptos de ideario e imaginario acuñados, por lo general, como sinónimos- que impactan sobre los comportamientos y, sobre todo, legitiman el poder. El imaginario social, argumenta Baczko (1991, p. 29), es una de las fuerzas reguladoras de la vida colectiva. Pero el adjetivo social connota dos aspectos de la "actividad imaginante":

Por un lado, la orientación de ésta hacia lo social, es decir, la producción de representaciones globales de la sociedad y de todo aquello que se relaciona con ella, por ejemplo, del "orden social", de los actores sociales y de sus relaciones recíprocas (jerarquía, dominación, conflicto, etc.), de las instituciones sociales, y en especial de las instituciones políticas, etcétera. Por otro lado, el mismo adjetivo designa la 
inserción de la actividad imaginante individual en un fenómeno colectivo (Baczko, 1991, p. 27).

Los imaginarios sociales no actúan individualmente, sino que son articulados con otros idearios y sus respectivos sistemas de símbolos (Baczko, 1991). Desde esta perspectiva, las representaciones simbólicas de futuro e innovación pueden ser rastreadas a través del análisis de sus producciones artísticas. En los próximos apartados, se reconstruyen las ideas, comportamientos, actitudes y conceptos que modularon los idearios de modernización en torno a los desarrollos de la técnica desde los albores del siglo XX, con el objetivo de profundizar en cómo los "signos investidos del imaginario" (Baczko, 1991, p. 29) fueron plasmados en obras visuales y literarias producidas por algunos movimientos de vanguardia latinoamericanos.

\section{Optimismo tecnológico: la noción de lo nuevo en los movimientos de vanguardia}

El enérgico enfrentamiento de los movimientos de vanguardia hacia la "institución-arte" (Bürger, 2009), y su lógica del arte por el arte, comprometió la adopción de nuevas técnicas, herramientas y materiales que permitieran integrar la actividad artística con la praxis vital. Es claro que la intención proclamada por las vanguardias de fundar un arte que quebrara el orden establecido trascendía el sentido estético; si bien respondía a la ilusión de promover una concepción artística alternativa, encarnaba también la utopía de transformación política y social.

Algunos artistas investigaron las posibilidades creativas inauguradas por las tecnología ${ }^{2}$ o, aunque no lo hicieran de manera explícita, reflexionaron sobre la omnipresencia de la máquina en el marco del crecimiento del capitalismo industrializado. En determinados casos, plantearon perspectivas irónicas que socavaban la instrumentalidad tecnológica: Man Ray, Marcel Duchamp y Francis Picabia, ${ }^{3}$ entre otros exponentes dadaístas, representaron máquinas humanizadas, incluso dispositivos inútiles y vulnerables, mientras que los trabajos de George Grosz y Kurt Schwitters ${ }^{4}$ abordaron las mutaciones humanas causadas por la

\footnotetext{
${ }^{2}$ Entre otros, László Moholy-Nagy, Naum Gabo, Antoine Pevsner, Vladimir Tatlin y El Lissitzky. Algunas de sus obras serán analizadas a continuación.

${ }^{3}$ Se podría mencionar aquí a Jean Tinguely. Aunque la obra de este artista, nacido en 1925, es posterior a las producciones de las vanguardias históricas, también constituye un exponente de la crítica hacia la glorificación tecnológica; en su caso, mediante la construcción de máquinas inútiles.

${ }^{4}$ Por ejemplo, Autómatas republicanos (1920) de George Grosz y Merzbild (1919) de Kurt Schwitters.
} 
incorporación de rasgos "maquínicos". La inclusión de la tecnología en algunas obras de vanguardia permitía liberar a aquella de su componente instrumental para cuestionar la asociación establecida por la burguesía entre tecnología y progreso, y disputar su noción del arte como práctica neutral, autónoma y orgánica:

En un nivel de representación más tradicional - que nunca fue abandonado del todo- la crítica radical de la vanguardia a los principios del iluminismo burgués y su glorificación del progreso y la tecnología se plasmó en pinturas, dibujos, esculturas y otros objetos artísticos en los cuales los seres humanos aparecen representados como máquinas y autómatas, marionetas y maniquíes, por lo general sin rostro, con cabezas hundidas, ciegos o con la mirada perdida en el espacio (...) En Dadá, la tecnología funcionó fundamentalmente como un vehículo para ridiculizar y desmontar la alta cultura burguesa y su ideología, y se le atribuyó en consecuencia un valor iconoclasta, en consonancia con el gesto anárquico del dadaísmo (Huyssen, 2006, pp. 32-33).

Por el contrario, otros movimientos dieron fe de un marcado optimismo tecnológico. La atracción ejercida por la máquina no fue privativa del futurismo, también signó el eje de acción del constructivismo ruso, el neoplasticismo y la Escuela de la Bauhaus, cuyos programas estimularon la relación entre el arte, la ciencia y la tecnología a fines de acercar la práctica artística a la vida y contribuir así con la proyección de una nueva realidad. Aaron Scharf (2006) describió claramente el rol significativo desempeñado por las tecnologías en la propuesta constructivista, como parte de un proyecto utópico que superaba al arte en sí mismo:

El constructivismo nunca tuvo la intención de ser un estilo abstracto en arte, ni siquiera un arte per se. En su esencia fue primero y sobre todo la expresión de una convicción muy motivada de que el artista podía contribuir a aumentar las necesidades físicas e intelectuales de la sociedad en su conjunto entrando en una relación directa con la producción de la máquina, la ingeniería arquitectónica, y los medios gráficos y fotográficos (Scharf, 2006, p. 160).

El constructivismo se colocó al servicio de la Revolución Rusa y surgió como expresión directa de la ideología marxista, en pos de expresar las aspiraciones revolucionarias del proletariado. Mario de Micheli (1979) recuerda una famosa secuencia de Lo viejo y lo пиеvo, film de Serguéi Eisenstein de 1929, en la cual un grupo de trabajadores rurales observa fascinado el funcionamiento de una máquina descremadora automática. La profunda atracción ejercida por la tecnología -fuerza que decidía el porvenir de la nación en plena etapa de mecanización del campo (De Micheli, 1979)- permite entrever los imaginarios de modernización imperantes. La consolidación de una nueva estructura implicaba la erradicación del antiguo arte burgués, fundado en distinciones entre artes mayores y menores, 
y su sustitución por una nueva superestructura, es decir, una nueva práctica artística que fuera impulsada por artistas, científicos, técnicos e ingenieros, quienes se desempeñarían como constructores $^{5}$ activos de nuevas formas útiles.

Desde 1914, Vladimir -uno de los artistas más destacados del movimiento- exploró la incorporación de nuevos materiales como madera, metal y cristales rotos en instalaciones "no utilitarias" (Lodder, 1988) que avanzaban hacia el espacio real, como sus construcciones en relieve y contra-relieves de esquina; pocos años después, el artista reveló las búsquedas constructivistas por emplear la tecnología en proyectos artísticos que al mismo tiempo perseguían fines sociales. El Monumento para la Tercera Internacional, desarrollado entre 1917 y 1920, fue un proyecto utópico que nunca llegó a concretarse debido a las complejidades técnicas que encarnaba. La idea original consistió en una enorme estructura de hierro en forma de espiral de casi cuatrocientos metros de altura, en cuyo interior diferentes cuerpos de cristal girarían sobre su propio eje a distintos tiempos. Un cubo rotaría anualmente y contendría las actividades legislativas; una pirámide completaría su giro en un mes y estaría dedicada a las actividades ejecutivas; y un cilindro daría la vuelta en un día y funcionaría como un centro de información para las masas con un telégrafo, una estación de radio y un sector para la publicación de panfletos. Un dispositivo de proyección, contenido en un segmento esférico, remataría la parte superior del monumento.

Por su parte, el realismo constructivista de Naum Gabo y Antoine Pevsner (1979) también incitó la alianza entre el arte y la tecnología, y la relación entre la práctica artística y el trabajo ingenieril, aunque desde una línea menos productivista y utilitaria que la de Tatlin:

Con la plomada en la mano, con los ojos infalibles como dominadores, con un espíritu exacto como un compás, edificamos nuestra obra del mismo modo que el universo conforma la suya, del mismo modo que el ingeniero construye los puentes y el matemático elabora las formulas de las órbitas (Gabo y Pevsner, 1979, p. 327).

Gabo y Pevsner (1979) introdujeron la noción de "ritmos cinéticos" como vía hacia la percepción del tiempo real. Precisamente, las tecnologías serían los medios propicios para materializarlos. Construcción cinética: onda estacionaria fue una escultura mecánica realizada por Gabo en 1920 para explicar a sus alumnos los principios del cinetismo, y

\footnotetext{
${ }^{5}$ En 1922, Aleksei Gan publicó El constructivismo. Allí definió a la tectónica, la factura y la construcción como los tres principios básicos del constructivismo; además, sostuvo que el artista es un "constructor de masas". La noción de construcción reapareció en el Manifiesto de 1923, firmado por el poeta Vladimir Mayakowski y publicado en el primer número de la revista LEF (Frente de Izquierda de las Artes), donde se afirma que el arte es "construcción de la vida".
} 
consistía en una barra metálica dispuesta sobre una base de madera que era accionada por un motor eléctrico. Al presionar un botón, la barra comenzaba a oscilar generando ondas estacionarias, las cuales producían la ilusión de tridimensionalidad. De esta manera, componentes estéticos y físicos convergían en una obra que investigaba los propios aspectos plásticos y cinéticos.

Mientras el constructivismo se desarrollaba en Rusia, en los Países Bajos nacía el neoplasticismo, puntualmente en 1917, cuando Piet Mondrian conoció a Theo Van Doesburg -encuentro que desembocaría en la creación de la revista De Stijl-. Además, la Primera Guerra Mundial suscitó el deseo de renovación artística que sería expresado en una concepción utópica y espiritual de la obra de arte como totalidad objetiva, devenida de la filosofía neoplatónica del matemático M. H. J. Schoenmaekers y la arquitectura de Frank Lloyd Wright. El neoplasticismo buscó la eliminación de toda expresión subjetiva de los artistas en sus producciones, la abstracción absoluta, la implementación de líneas rectas horizontales y verticales, y el trabajo con colores puros y planos. Indefectiblemente, la soberanía de la máquina funcionaba como contrapunto de las técnicas artesanales que seguían conduciendo hacia un arte individual. En tanto, la técnica abría el camino hacia la industrialización permitiría la despersonalización de las obras.

Uno de los integrantes de De Stijl que plasmó este optimismo tecnológico fue el arquitecto holandés Jacobus Johannes Pieter Oud. En 1918, la revista De Stijl publicó su ensayo titulado "Arte y máquina" donde, apelando a un esquema hegeliano, el artista sostuvo que la esencia del nuevo estilo derivaría de la unión de dos tendencias: una adjetivada como "positiva", debido a que proporcionaría expresión artística a los productos técnicos; otra, "negativa", la cual alcanzaría el funcionalismo a través de la abstracción. Según Oud (1918), la universalidad del arte podía ser conseguida mediante los materiales y métodos de producción, porque estos permiten dar expresión plástica al espíritu. Cuando el arquitecto se preguntó si aquella forma era provista por la mano del artista o por la máquina, respondió en los siguientes términos:

Para el artista moderno la futura línea de desarrollo debe inevitablemente conducir hacia la máquina, aunque al principio esta tendencia puede ser vista como herejía. No solo porque la máquina puede dar una mayor expresión plástica que la mano, sino porque desde un punto de vista social y económico la máquina es el mejor medio de manufactura de productos que serán de mayor beneficio para la comunidad que los productos del arte del presente, que solo alcanzan a los ricos (Oud, 1918, s. p.). 
La última fase del escrito de Oud sintetizaba su visión utópica: "la obra de arte será producida por la máquina”. En este caso, la utopía tecnológica se ve radicalizada por el hecho de que las tecnologías no se incorporaron de manera explícita en las obras del neoplasticismo; se encuentra aquí una diferencia significativa con respecto al optimismo del constructivismo ruso. En el caso de De Stijl, la relación entre la noción de vanguardia y su posicionamiento hacia el desarrollo de la máquina no se encontraron alineados con un programa político, sino que intentaron fundar nuevos valores artísticos con independencia de la realidad material. Para los artistas neoplasticistas, las tecnologías podían resultar útiles porque habilitaban la despersonalización de la obra de arte y la creación de un arte abstracto, de base espiritual y colectiva.

La conexión entre el arte y la técnica también caracterizó a la Escuela de la Bauhaus, fundada por Walter Gropius en la República de Weimar en 1919. Devenida de la fusión de la Escuela de Bellas Artes y la Escuela de Artes y Oficios de Weimar, la misión central de la Bauhaus consistió en promover la unión entre las bellas artes y las artes aplicadas, en función de la creación de una obra de arte total. Según el propio Gropius, sus antecedentes intelectuales fueron John Ruskin y William Morris en Inglaterra, quienes en el siglo XIX ya habían postulado la necesidad de erradicar la alineación producida por el trabajo con la máquina y de valorizar las prácticas artesanales. Asimismo, Henry van Der Velde, figura destacada del art nouveau, aspiró a renovar la artesanía a través de la incorporación de técnicas mecanizadas; participaron también Joseph Maria Olbrich y Peter Behrens, convocados por el Gran Duque de Hesse para integrar la Colonia de Artistas en Darmstadt, entre cuyos objetivos propuso estimular el artesanado; y Hermann Muthesius, autor de la Deutscher Werkbund, una asociación que agrupó el arte, la arquitectura y la industria al defender la incorporación de la máquina en la realización de las obras y la tipificación de la producción (Wick, 2007).

Los talleres impartidos en los primeros tiempos de la Escuela de la Bauhaus apuntaban a derribar las fronteras tradicionales entre la actividad de los artistas y los artesanos. De allí que los talleres dedicados a los oficios -cerámica, metal, tejido y carpintería, entre otrosconvivieran con los cursos dedicados a la composición, la morfología y el color. La idea de que el aprendizaje de diferentes técnicas manuales conducía a la síntesis estética fue encarnada por la labor de Johannes Itten, artista y docente a cargo del curso introductorio impartido en la Bauhaus, quien impulsó una línea expresionista, introspectiva y espiritual, la cual perduró en la Escuela hasta 1922, cuando el antiguo lema que defendía la unidad del arte 
y la artesanía fue sustituido por la idea de "arte y técnica: una nueva unidad", en el marco de una Alemania que se recuperaba de la inflación de posguerra y poco a poco fortalecía su industria. Además, en 1923 László Moholy-Nagy sustituyó a Itten como docente del curso introductorio, de manera que la perspectiva romántica, sustentada en la noción medieval de oficio y abocada al trabajo manual, fue reemplazada por la incorporación de técnicas industriales. El artista húngaro sumó nuevos materiales, entre ellos cristal y plexiglás, y motivó la experimentación con medios hasta entonces inexplorados, como fotomontajes y esculturas cinéticas y lumínicas. Una de las obras paradigmáticas realizadas por MoholyNagy en aquella época fue su Lichtrequisit einer elektrischen Bühne, conocido en español como Modulador espacio-luz. Se trató de un dispositivo desarrollado entre 1922 y 1930 , exhibido en una de las salas de exposición que integraron la sección alemana de la exposición anual de la Sociedad de Artistas Decoradores de París en 1930, a cargo de Gropius. El artista presentó diferentes objetos e imágenes, como la proyección de diapositivas con imágenes de telescopios, aviones y distintas escenas cotidianas que permitieran proporcionar una imagen global de la cultura alemana. Una de las áreas de la sala otorgada a Moholy-Nagy se dedicó a la escenografía teatral, con sus proyectos escenográficos para obras de teatro, así como una pantalla traslúcida, detrás de la cual colocó el Modulador espacio-luz. La pieza estaba provista de una serie de placas perforadas, barras y otros elementos que se movían por la acción de un motor y generaban distintos efectos lumínicos, provocados por las luces del compartimento interior del dispositivo. En el Manifiesto Sistema Constructivo-DinámicoFuerza, publicado en Der Sturm en 1924 y firmado por László Moholy-Nagy y Alfred Kemény, ya se defendía el reemplazo de la construcción estática por una construcción dinámica, cuyos materiales funcionaran como "portadores de fuerzas" (Moholy-Nagy y Kemény, 2009, p. 378).

A partir de 1923, la Bauhaus se volcó hacia el diseño de prototipos para la industria, un giro que procuraba independizar a la Escuela de los fondos públicos. Rainer Wick (2007) argumentó que el programa de la Bauhaus aspiraba a la síntesis estética y proclamaba la síntesis social, vale decir, para orientar la producción estética hacia las necesidades de amplios círculos de población. Desde este punto de vista, el empleo de las tecnologías y el proceso de industrialización permitían concretar fines sociales. 


\section{Utopías latinoamericanas}

Como contrapartida del optimismo tecnológico característico de algunos movimientos de vanguardia europeos, en Latinoamérica surgieron perspectivas que cuestionaron la glorificación de la máquina y plantearon actitudes críticas hacia la transposición neutral de discursos exógenos. Rodrigo Alonso (2015) señaló que Vicente Huidobro, César Vallejo y José Carlos Mariátegui no mostraron una fascinación radical por los avances de la técnica. Sus posturas no eran reaccionarias porque no se enfrentaban a los cambios tecnológicos, "sino a su aceptación ensalzadora y acrítica" (Alonso, 2015, p. 185). En el artículo "Futurismo y maquinismo", Huidobro (1976) observó que los aportes del futurismo debían estar acompañados por otra clase de sensibilidad que trascendiera el frecuente "maquinismo" de la época. El mero hecho de hacer alusión a las tecnologías no suponía necesariamente un gesto innovador:

Los poetas que creen que porque las máquinas son modernas también serán modernos al cantarlas se equivocan absolutamente. Si canto al avión con la estética de Víctor Hugo, seré tan viejo como él; y si canto al amor con una estética nueva, seré nuevo (Huidobro, 1976, p.720).

En el terreno de las artes visuales, se observa una dinámica semejante: muchos artistas optaron por elaborar lenguajes artísticos propios y defender la consolidación de una tradición local, aunque en general se fusionaron con elementos proporcionados por las tendencias provenientes del Viejo Mundo. Por ejemplo, el universalismo constructivo, la vanguardia antropofágica y el muralismo mexicano constituyeron propuestas sin precedentes que procuraron colaborar con la construcción identitaria de sus respectivos países, sin excluir el pasado local previo a la conquista. El retrato del indígena, la inclusión de símbolos prehispánicos o la representación del paisaje nativo, todos ellos desprovistos del exotismo de la mirada europea, ${ }^{6}$ fueron combinados con los códigos, estéticas y enseñanzas extranjeras.

El estridentismo demostró tanto la atracción ejercida por expandir las máquina como la confluencia entre recursos foráneos y lenguajes vernáculos en el campo de la literatura y las artes plásticas. Influido por el ultraísmo español, el movimiento fue fundado en México, en

\footnotetext{
${ }^{6}$ La mirada exótica sobre el territorio americano, afín al espíritu romántico, fue plasmada en los trabajos de los artistas viajeros del siglo XIX, como Moritz Rugendas, Daniel Thomas Egerton, Claudio Linati, Federico de Waldeck, Guillermo Dupaix y Alexander von Humboldt. Este último fue un naturalista alemán que permaneció en América entre 1799 y 1804, recorriendo Venezuela, Cuba, México, Ecuador, Perú y Colombia. Durante sus viajes tomó notas y realizó dibujos de la arquitectura, el paisaje y la indumentaria prehispánicos.
} 
1921, por Manuel Maples Arce, a partir de la redacción del manifiesto titulado "Actual n.1, Hoja de Vanguardia, Comprimida Estridentista del poeta Manuel Maple Arce". Entre sus integrantes también se encontraban Germán List Arzubide, Germán Cueto, Fermín Revueltas, Luis Quintanilla del Valle, Ramón Alva de la Canal, Leopoldo Méndez y Arqueles Vela. Los artistas estridentistas coincidieron con el futurismo en su atracción por los desarrollos tecnológicos de la vida moderna:

Es necesario exaltar en todos los tonos estridentes de nuestro Diapasón propagandista, la belleza actualista de las máquinas, de los puentes gímnicos reciamente extendidos sobre las vertientes por músculos de acero, el humo de las fábricas, las emociones cubistas de los grandes trasatlánticos con humeantes chimeneas de rojo y negro, anclados horoscópicamente -Ruiz Hidobro- junto a los muelles efervescentes y congestionados, el régimen industrialista de las grandes ciudades palpitantes, las blusas [sic] azules de los obreros explosivos en esta hora emocionante y conmovida (Maples, 1921, s. p.).

El movimiento mexicano, por su parte, no buscó reproducir la velocidad y el frenesí de las ciudades de principios de siglo -aspectos que habían cautivado a los artistas del futurismo italiano-, sino expresar las transformaciones en la sensibilidad producidas en el nuevo contexto moderno. Tampoco el estridentismo apeló a una estética futurista haciendo foco en el porvenir; en cambio, se constituyó como un movimiento "actualista" y "presentista" que aprovechó el espíritu turbulento y provocador gestado por la Revolución Mexicana para generar una renovación estética, política y social (Prieto, 2011, s. p.). A través del análisis de La señorita Etcétera, de Arqueles Vera, y el poema Urbe, de Maples Arce, María Cecilia Lourdes Pardo (2010) destacó que, en la literatura estridentista, las frases incoherentes y la sintaxis interrumpida evidencian el ritmo agitado de la ciudad, cuya dinámica es traducida a nuevos principios narrativos, en lugar de ser representada de manera mimética. Del mismo modo, las líneas diagonales acentuadas que atraviesan las xilografías Estación de radio de Estridentópolis y Edificio del movimiento estridentista, ambas de Ramón Alva de la Canal, destacan la monumentalidad de las construcciones y logran captar el ímpetu de la urbe. La primera de ellas presenta el proyecto de una estación de radio para Estridentópolis, denominación acuñada para designar a la ciudad de Xalapa, donde los estridentistas se establecieron hacia 1925. El punto de vista bajo de la representación exagera la altura de las torres que rematan el edificio y, en consecuencia, instaura una perspectiva vertiginosa. Los orígenes de la radiofusión en México se remontan a 1921. Ese año, Constantino de Tárnava ingeniero mexicano formado en los Estados Unidos- creó la primera radiodifusora del país, cuyo slogan era "La voz de Monterrey desde 1921". Poco tiempo después, Maples leyó su 
poema T.S.H. (1923) a través de la radio y publicó su libro Andamios Interiores. Poemas Radiográficos (1922). El nuevo medio permitió ampliar la difusión de las obras estridentistas, a la vez que encarnaba el emblema por excelencia de la modernidad.

\section{Cultura de mezcla: criollismo, modernidad e invención}

$\mathrm{Al}$ analizar los movimientos argentinos de vanguardia, se detectó un proceso similar con respecto al de otros territorios latinoamericanos. En el primer capítulo del libro Una modernidad periférica: Buenos Aires 1920 y 1930, titulado "Buenos Aires: una ciudad moderna", Beatriz Sarlo (2007) ofrece una descripción minuciosa de algunas de las obras que Xul Solar exhibió en Buenos Aires a partir de 1924, fecha de su regreso al país luego de haber residido doce años en Europa. La geometrización de las figuras que pueblan sus composiciones y el carácter místico y simbólico que las caracteriza son algunos de los rasgos derivados de las influencias europeas, como la vertiente visionaria-utópica del expresionismo alemán, de acuerdo con la cual la arquitectura permitió la unión del hombre y las prácticas artísticas, pero también los artistas de Die Brüke (1905-1913) y la impronta espiritual de Der Blaue Reiter (1911-1914), fundamentalmente a través de la obra de Paul Klee y Wassily Kandinsky.

La reconstrucción de Sarlo (2007) captó el sistema iconográfico característico del trabajo de Xul Solar, que combina banderas, efigies precolombinas, signos astrológicos y cabalísticos, construcciones fantásticas, personajes híbridos antropo-zoomorfos, panlengua, neocriollo y "modernas quimeras" (Sarlo, 2007, p. 13): hombres con cabeza de ave, ruedas en los pies; chimeneas, escaleras y anclas desprendidas desde el centro del cuerpo y hélices en el cuello, que les permiten sobrevolar un paisaje esquemático y descontextualizado. Estas últimas imágenes refieren a Dos mestizos de avión y gente (1935), realizada en lápiz acuarela y grafito sobre papel. El mestizaje propio de las obras de Xul Solar, compuestas por la coexistencia de elementos heterogéneos, es leído por Sarlo (2007) como un "rompecabezas de Buenos Aires" (p.14), cuya mezcla, asimismo, resonó en la esfera cultural. Los imaginarios de modernización argentinos fueron modulados por una doble tendencia que, de forma simultánea, "intersectó modernidad europea y diferencia rioplatense, aceleración y angustia, tradicionalismo y espíritu renovador, criollismo y vanguardia” (Sarlo, 2007, p. 15).

Entre los años veinte y treinta, en Buenos Aires no solamente se mezclaban idiomas, como efecto del proceso migratorio iniciado hacia fines del siglo XIX, sino que también se 
fusionaban paisajes diversos, donde convivían cables de alumbrado eléctrico, medios de comunicación novedosos como la radio y la ramificación del tranvía, con terrenos baldíos que aún no habían sido incorporados al nuevo diseño urbano. Se trataba de un proyecto en vías de concreción que sorprendía a los habitantes que todavía recordaban la fisonomía de la Buenos Aires de antaño. Los vestigios de la ciudad del pasado comenzaban a solaparse con los primeros signos de la capital moderna, configurando una "cultura de mezcla" que resultaba de la coexistencia de "elementos defensivos y residuales junto con los programas renovadores; rasgos culturales de la formación criolla al mismo tiempo que un proceso descomunal de importación de bienes, discursos y prácticas simbólicas” (Sarlo, 2007, p. 28).

Aquella dinámica de superposición de tiempos y paisajes diversos recuerda la travesía de Robert Smithson hacia el condado de Passaic, en Nueva Jersey, quien en 1967 se lanzó a recorrer un "suburbio industrial corroído por el torbellino del progreso" (Speranza, 2017, p. 27). En su escrito "A Tour of the Monuments of Passaic, New Jersey”, publicado ese mismo año en la revista Artforum como "The Monuments of Passaic", el artista detalló una serie de monumentos que encontró durante su paseo -grúas, tuberías, pilares de concreto, cráteres artificiales convertidos en estanques de agua-e ilustró las descripciones con fotografías de las distintas vistas. Según Smithson (1967, p. 72), estas construcciones encarnaban "ruinas al revés" en una puesta en escena que adjetivó "anti-romántica”, debido a que las edificaciones existían como restos incluso antes de haber ser erigidos. Graciela Speranza (2017) resumió la operación del artista como un acto de creación de monumentos del paisaje posindustrial trastornado por la modernización urbana, en un doble gesto conceptual mediante el cual no solo los monumentos fueron fotografiados, sino además fueron nombrados ("Monumento puente mostrando las aceras de madera", "Monumento con pontones", "Monumento de la gran tubería" y "Monumento fuente").

Las transformaciones del paisaje ocasionadas por la vorágine del progreso reaparecen en obras más recientes, como en SEFT-1 (Sonda de Exploración Ferroviaria), ${ }^{7}$ un proyecto de arte e investigación encauzado por los mexicanos Iván Puig y Andrés Padilla Domene con la intención de reflexionar sobre las ruinas del programa modernizador en territorios latinoamericanos, vestigios calificados por los artistas como "ruinas modernas" (Padilla y Puig, 2011, p. 65). SEFT-1 consistió en un vehículo dotado de ruedas para desplazarse por tierra, así como de un sistema $\mathrm{Hi}$-Rail que posibilitaba su trayecto por los rieles de las vías a través de ruedas metálicas, destinado a recorrer espacios ferroviarios caídos en desuso luego

\footnotetext{
${ }^{7}$ Documentación del proyecto disponible en http://www.seft1.com
} 
del proceso de privatización de los ferrocarriles en la década del noventa. Provisto de una estética retrofuturista, el vehículo con capacidad para dos "ferronautas" fue diseñado sobre una estructura de camioneta revestida de aluminio que buscaba reconstruir la imagen del futuro que se tenía en el pasado y cuestionar su asociación recurrente con las ideas de progreso y modernidad:

Su referencia estética está basada en la noción de progreso vinculada al futuro, tal como lo planteó la modernidad, en donde la razón y la tecnología son consideradas como solución a los problemas de la humanidad y se disponen al servicio del bien común; el proyecto revisa este fracaso de futuro y el desmoronamiento del metarrelato que predica la relación positiva entre la ciencia y el bienestar social. Actúa a su vez como máquina del tiempo, no solo por la inspección histórica sino porque en sus exploraciones pasará por lugares que funcionan aún como sociedad agrícola, industrial, post-industrial, hasta la sociedad de la información, coexistiendo en un mismo espacio y poniendo en entredicho el concepto del desarrollo lineal y sucesivo (Puig y Padilla, 2006-2011, párr. 7).

Entre 2006 y 2011, la sonda exploratoria recorrió rutas férreas de México y Ecuador. Durante sus viajes, los artistas tomaron fotografías, grabaron videos y entrevistaron habitantes de los sitios que visitaron. Estos materiales iban siendo compartidos en la página web del proyecto que funcionaba como una bitácora de la travesía. Un mapa mostraba la localización del vehículo y los registros obtenidos en los diferentes puntos del itinerario. Asimismo, los artistas fueron creando un "muestrario lunar", integrado por restos de la maquinaria ferroviaria, desechos tecnológicos y fragmentos de la naturaleza encontrados en el camino. Todos estos materiales configuran un "archivero de escombros" (Larios, 2011, p. 114): hojas de la barranca de Metlac, plumas, trozos del durmientes, pedazos de vidrio, cortezas de óxido, piedras volcánicas, resortes, tuercas y tornillos de vías -piezas cuidadosamente numeradas y clasificadas- conforman un repertorio de testimonios donde confluyen "rumores colectivos y densidades imaginarias" (Larios, 2011, p. 108). Mientras que Smithson (1967) identificaba a las ruinas anti-románticas como los vestigios industriales que precedían la culminación de su construcción, Padilla y Puig (2011) revelan las ruinas modernas que sobrevienen a la destrucción en tanto "muestras post-catástrofe" (Larios, 2011, p. 110). En este sentido, para Mariela Yeregui (2013) SEFT-1 condensa el carácter periférico, ambiguo y heteróclito de la modernidad latinoamericana: "donde conviven trenes, burros, autopistas y polvorientos caminos, eurocentrismo remilgado y regionalismo exacerbado" (p. 12).

Si las ruinas de Passaic, nacidas del avance de las construcciones posindustriales sobre el entorno natural en una suerte de paisaje "a medio hacer", y los vestigios de los espacios 
ferroviarios mexicanos y ecuatorianos abandonados conducen a revisar el ritmo lineal y unidireccional del progreso, en la sociedad porteña de las primeras décadas del siglo todavía prevalecía la esperanza hacia el proyecto modernizador.

Una arista de las complejidades inherentes a la cultura de mezcla es advertida en la configuración de imaginarios de modernización divergentes, encarnados en determinadas figuras que asumieron los avances de la técnica desde perspectivas antagónicas. La fascinación provocada por la ciencia y la tecnología no solo operó como ícono de lo nuevo en las búsquedas de las vanguardias estéticas, sino que también integró los "saberes del pobre" (Sarlo, 1992, p. 9) que mixturaban fragmentariamente conocimientos tecno-científicos y paracientíficos diversos -astrología, alquimia, hipnosis-, a la vez que compensaban las diferencias culturales entre la esfera letrada y la cultura de los sectores populares, sobre todo de origen inmigratorio (Sarlo, 1992, p. 13). Poco a poco nacía la figura del inventor. Frente a los saberes teóricos del intelectual, los "amateurs de lo nuevo" (Sarlo, 1992, p. 90), de origen popular, trabajaban de modo autodidacta estimulados por la ilusión de obtener fama y riqueza, mediante un saber hacer que convertía a la técnica en la "literatura de los humildes" (Sarlo, 2007, p. 57). Esta figura del inventor resulta paradigmática en algunas obras de Roberto Arlt, en particular El juguete rabioso (1926), Los siete locos (1929) y Los lanzallamas (1931), cuyos personajes denotan "saberes o prácticas que entrecruzan modernidad y arcaísmo, ciencia y paraciencia, empirismo y fantasías suprasensoriales" (Sarlo, 2007, p. 55), vale decir, otra de las expresiones de la cultura de mezcla forjada en Buenos Aires en los años veinte y treinta.

\section{Artistas inventores}

Fernando Crudo -formado como químico industrial en una escuela politécnica de Buenos Aires- combinó técnicas litográficas, fotográficas y fonográficas que resultaron en la creación de su fotoliptófono, concebido en la década del veinte y patentado en 1934. Basándose en la reciente tecnología del cine sonoro, donde una fuente de luz impactaba en la tira de oscilogramas y las variaciones lumínicas captadas por un sensor eran traducidas en las modulaciones de sonido, Crudo diseñó un artefacto que permitía grabar y reproducir audio tomando como soporte a una hoja de papel. El dispositivo consistía en un cilindro motorizado que contenía una película fotosensible. Al girar, una lámpara proyectaba luz sobre él, al tiempo que un micrófono relevaba las variaciones sonoras y las convertía en cambios de 
tensión. De acuerdo con las descripciones de Ianina Canalis (2010), estudiosos de la historia del fotoliptófono en el marco del proyecto de investigación "Reconstrucción de tecnologías antiguas de grabación de sonidos", radicado en la Universidad Nacional de Lanús (Buenos Aires):

Para lograr las escalas de grises, se amplificaba la señal del micrófono para llegar con mayor nivel a un tubo de vidrio encorvado que contenía gas de neón enrarecido que, según la corriente que pasaba por él, emitía una luz actínica (acción químicas de las reacciones luminosas) proporcional a la corriente que lo atravesaba, la cual era reflejada por un reflector de metal pulido que concentraba la luz sobre el objetivo. Entonces la luz emitida quemaba la información de audio sobre la película sensible a la luz (Canalis, 2010, p. § 3.3.1).

Cuando finalizaba el proceso de grabación, la película mostraba un conjunto de líneas que contenían la información sonora y, luego de ser revelada, se obtenían matrices litográficas para imprimir páginas sonoras. A través de un proceso inverso al de grabación, las páginas debían ser colocadas en el fotoliptófono para que las líneas fueran iluminadas. Una célula fotosensible captaba las variaciones de luz, las convertía en energía eléctrica y, finalmente, los sonidos eran amplificados por un parlante. Canalis y Petrosino (2014) demostraron que en julio de 1933 el diario francés Le Journal publicó una página que contenía unos minutos de sonido impreso. Según sus investigaciones, habría sido el primer intento de difundir sonido en un medio masivo de comunicación.

Fernando Crudo constituye un exponente de la figura del inventor-artista, en tanto aplicó saberes técnicos para el desarrollo de una máquina que, al permitir transformar los procedimientos de grabación y reproducción de sonido, pudo haber revolucionado el mundo de la música de la década del treinta: posteriormente, en los años cuarenta, Gyula Kosice fusionó medios tradicionales, herramientas tecnológicas e imaginarios científicos, de cara a fundar una práctica artística que se integrara a la vida.

La noción de invención operaba a nivel pragmático, pero también poético. En 1944, Kosice había formado parte del núcleo editor de Arturo. Revista de Artes Abstractas, junto con Carmelo Arden Quin, Rhod Rothfuss y Edgar Bayley. La revista fue el órgano difusor del arte concreto rioplatense. Según Mario Gradowczyk (2006), esta vanguardia combativa, constituida entre Argentina y Uruguay, planteó una voluntad irrefrenable por inventar, regida por la confianza de que el proyecto marxista lograría consolidar un mundo nuevo. 
El único número de la revista que fue publicado incluyó textos y poemas de Kosice, Arden Quin, Bayley y Rothfuss. También se sumaron los de Joaquín Torres García, ${ }^{8}$ Vicente Huidobro y Murilo Mendes, ${ }^{9}$ además de las reproducciones de Maldonado, Rothfuss, Prati, Vieira da Silva, Augusto Torres, Torres García, Kandinsky y Mondrian. En la retiración de cubierta figuraba la definición del término "inventar", como el hallazgo o descubrimiento de una fuerza de ingenio hasta entonces desconocida. La "invención" propiamente dicha era pensada como la acción o el efecto de inventar, aunque ubicada en las antípodas del automatismo:

La invención era precisa, científica, delimitada y surgía a través de un proceso de intelectual que reorganizaba ese proyecto creativo. "INVENCIÓN CONTRA AUTOMATISMO” implicaba entonces el reconocimiento superador de la técnica surrealista y la proposición de un segundo momento, un nuevo estadio en la creación estética (García, 2011, p. 32).

De esa forma el grupo proclamaba la primacía del concepto de invención sobre la impronta onírica del surrealismo, al igual que desdeñaba la personalización de la obra de arte característica de otras tendencias que hacían foco en la subjetividad del artista y en las cualidades expresivas, simbólicas y representativas. En el primer escrito que aparece en Arturo, firmado por Arden Quin, el autor demuestra la influencia del materialismo histórico y deja en claro el interés del arte concreto por sintetizar las imágenes figurativas, mediante una conciencia ordenadora que lograra depurar el caos de la imaginación "aflorando en todas sus contradicciones" (Arden Quin, 1944, s. p.). El primitivismo expresivo, el realismo representativo y el simbolismo guiado por la significación eran contrastados con un período de recomienzo, concebido como un primitivismo moderno y científico según el propio concepto de invención (García, 2011).

El desarrollo de un lenguaje artístico reducido a los elementos plásticos puros fue asimismo impulsado a través del marco recortado. En otro de los artículos compilados en la revista, titulado "El marco: un problema del plástica actual”, Rothfuss (1944) aseveraba que

\footnotetext{
${ }^{8}$ En 1935, Arden Quin había conocido en Montevideo a Joaquín Torres García, cuya obra influenció fuertemente a los artistas concretos rioplatenses. Además, el uruguayo exhibió sus obras en Buenos Aires, en las galerías Müller (1942) y Comte (1944), y sus ideas se difundieron a partir de 1944, cuando la editorial Poseidón publicó El Universalismo Constructivo. Contribución a la unificación del arte y la cultura de América. Por otro lado, Rothfuss estrechó una amistad con Torres García, su maestro. Por motivos de extensión, aquí no ahondamos en las diferentes influencias que recibió el grupo nucleado en torno a la revista Arturo. Para ampliar la trama de relaciones establecida entre las distintas propuestas constructivas, véase García (2011) y Rossi (2016).

${ }^{9}$ Entre los poemas de estos autores incluidos en la revista, se encuentran "Una mujer baila sus sueños", de Vicente Huidobro; "Novísimo Orfeo", "Homenaje a Mozart", "La libertad", "Momentos puros", "La operación plástica” y "La vida cotidiana”, de Murilo Mendes; y "Divertimento”, de Joaquín Torres García.
} 
la obra debía comenzar y terminar en ella misma, motivo por el cual el borde no podía desempeñar un rol pasivo, sirviendo únicamente como marco regular. En cambio, era preciso que estuviera "rigurosamente estructurado de acuerdo a la pintura" (Rothfuss, 1944, s. p.). Tanto Arden Quin como Rothfuss enfatizaron la "rigurosidad" del quehacer artístico e inauguraron una concepción de las artes que insistía en su aspecto racional.

Estas ideas continuarían siendo promovidas incluso luego de la división de los artistas en 1945 y la subsiguiente conformación del grupo Madí y la Asociación Arte ConcretoInvención. En el "Manifiesto Madí", publicado en el número 0 de la revista de la agrupación integrada por Kosice, Arden Quin y Rothfuss, entre otros, se oponían a los "movimientos intuicionistas" que habían provocado que el inconsciente triunfara sobre el "análisis frío, el estudio y la detención rigurosa del creador ante las leyes del objeto a construirse" (Kosice, 1947, s. p.). Para terminar con la "conciencia paralizada por sus contradicciones sin solución, impermeabilizada a la renovación permanente de la técnica y el estilo", los artistas madí llevaron a fondo la experimentación con el marco recortado, la pintura plana sobre superficies frecuentemente curvas y la conjunción de elementos geométricos articulados, guiados por las ideas de invención ("método superable") y creación ("totalidad incambiable"). Por su parte, la Asociación Arte Concreto-Invención también promovió el concepto de invención. En 1945, Tomás Maldonado, Enio Iommi, Claudio Girola, Alfredo Hlito y Lidy Prati organizaron una exposición en el taller de Maldonado. Un año después, el grupo mostró sus obras en el Salón Peuser, donde se sumaron Edgar Bayley, Manuel Espinosa y otros artistas. Allí repartieron el "Manifiesto Invencionista", que tiempo más tarde sería reimpreso en el primer número de la revista Arte-Concreto Invención. Así como en 1909 los futuristas habían declarado que un automóvil estrepitoso era considerablemente más bello que la sagrada Victoria de Samotracia, el grupo rioplatense bregó por la desaparición de la estética idealista de base representativa, aún anclada en la vieja noción de belleza, y su reemplazo por una "estética científica":

La estética científica reemplazará a la milenaria estética especulativa e idealista. Las consideraciones en torno a la naturaleza de lo Bello ya no tienen razón de ser. La metafísica de lo Bello ha muerto por agotamiento. Se impone ahora la física de la belleza (...). Por el júbilo inventivo. Contra la nefasta polilla existencialista o romántica. Contra los subpoetas de la pequeña llaga y del pequeño drama íntimo. Contra todo arte de élites. Por un arte colectivo (...). Lo fundamental: rodear al hombre de cosas reales y no de fantasmas. El arte concreto habitúa al hombre a la relación directa con las cosas y no con las ficciones de las cosas. A una estética precisa, una técnica precisa. La función estética contra el "buen gusto". La función blanca. NI BUSCAR NI ENCONTRAR: INVENTAR (AAVV, 1946, p. 8). 
García (2011, p. 66) explica que aunque en Arturo el concepto de invención apuntaba a superar el automatismo surrealista para luego racionalizar aquellas primeras expresiones desordenadas, aún se hacía mención a una primera instancia creativa libre. Sin embargo, el invencionismo se consolidó como término equivalente al de arte concreto, en estrecha correlación con las ideas de Van Doesburg en torno al grupo Art Concret, luego recuperadas por Max Bill, cuyos planteos repercutirían en el ámbito latinoamericano de la década del cincuenta.

También el primer número de la revista Arte Concreto-Invención publicó el escrito "Sobre invención poética", firmado por Edgar Bayley, quien un año antes había redactado el manifiesto titulado "La batalla por la invención" para el segundo número de los cuadernos Invención. En ambos textos se certificaba la idea de invención como la creación de objetos concretos que permitieran construir una nueva realidad, prescindiendo de la reproducción mimética propia del arte figurativo. El escrito de 1946 alegaba que el poema debía constituir un hecho en sí mismo: "El poeta no canta ya parcelas del mundo, porque ha comprendido que su oficio no reside en la mera enunciación de objetos, sino, en el más esencial, de producir en cada hombre una relación poética con la totalidad de las cosas y de las situaciones" (Bayley, 1946, p. 13). En definitiva, la invención implicaba la articulación entre conceptos, ideas y recursos previamente inexistentes. En palabras de Bayley "la poesía invencionista persigue una familiaridad con lo desconocido" (1946, p. 13).

No obstante, el acto de invención, junto con su carácter objetivo y eventualmente funcional, fue en general asociado a los campos de la ciencia y la tecnología, mientras que el arte quedó relegado al terreno de lo subjetivo (Gontijo, 2016, p. 14). Desde un enfoque simondoniano (Simondon fue reticente a la teoría de las "dos culturas", formulada por Charles Snow en 1959), Juliana Gontijo (2016, p. 17) recuperó la idea de invención como "energía informada" (Simondon, 2013, p. 81) e identificó en sus tesis doctoral una "inventiva tecnopoética" que funcionaría como táctica de resistencia hacia los procesos de subjetivación devenidos de las "herencias de modernidad fallidas y el capitalismo cognitivo posfordista". Sus hipótesis se fundamentan en una serie de proyectos argentinos y brasileños que cuestionan el progreso técnico lineal, a través de la subversión de las funciones originales de las tecnologías empleadas por las obras y la ruptura con la autonomía del arte proclamada por la modernidad estética (Gontijo, 2016, p. 18). Valentina Montero (2015, p. 546) destacó que en Chile estas operaciones de desvío reciben el apelativo de "hechizo", un término que en español antiguo significaba "malhecho" o "falsificado", posteriormente reemplazado por su 
connotación mágica. Los ensamblajes, gambiarras $^{10}$ y prácticas artísticas sustentadas en bajas tecnologías, en tanto desvían las funciones originales de los dispositivos, encarnan lo "hechizo" en el primer sentido, pero también requieren de habilidades específicas para lograr “deletrear el conjuro (código)" (Montero, 2015, p. 546).

Utopía, progreso y revolución fueron los tres pilares que definieron el guion curatorial de la exposición El futuro ya no es lo que era: imaginarios de futuro 1910-2010, curada por Rodrigo Alonso en 2009 e inaugurada en la salas de la Fundación OSDE, en Buenos Aires. La muestra discurría sobre cómo operaron aquellos tópicos en los idearios argentinos modulados desde el Centenario de la Revolución de Mayo. Este aspecto también fue trabajado por Margarita Gutman (2011), sus investigaciones acerca de la imaginación de futuro urbano en Buenos Aires entre 1900 y 1920, a través de ideas e imágenes anticipatorias del porvenir, indican que en las dos primeras décadas del siglo XX creció el interés por la ciencia y la tecnología y se cristalizó la creencia en su poder benéfico: ambas permitirían "iluminar los excitantes senderos de un futuro mejor, lleno de confort y velocidad" (Gutman, 2011, s. p.).

La conjetura que determinó el recorte curatorial de Alonso, integrado por obras realizadas en diversos medios, soportes y formatos (pintura, instalación, animación digital y fotografía), sostenía que los imaginarios de futuro se manifestaron de manera recurrente en el arte y la cultura argentinos a lo largo de la centuria a la cual estaba dedicada la muestra. Según explicaba el curador en la introducción del catálogo, la exhibición de materiales diversos procuraba revisar las propuestas, reflexiones y fantasías que podían proporcionar determinadas claves para pensar el presente (Alonso, 2009, p. 8).

Entre las obras incluidas en la sección dedicada a las utopías, se encontraba precisamente el proyecto de Gyula Kosice para Ciudad Hidroespacial (1960), cuyo diseño demostraba que las primeras incursiones latinoamericanas en los cruces entre el arte, la ciencia y la tecnología no solo estuvieron signadas por la búsqueda inventiva previamente analizada, sino también caladas por el programa utópico vanguardista. Para ese entonces, las obras de Kosice ya habían indagado en los usos creativos de las tecnologías. Sus esculturas de gas neón realizadas desde 1946 y otras obras como Una gota de agua acunada a toda velocidad (1948) -pieza cinética motorizada que por primera vez introdujo el agua en el

\footnotetext{
10 "Se trata de una palabra-concepto usada a larga escala en Brasil para considerar la resolución de problemas cotidianos de forma alternativa y barata, estableciendo funciones poco comunes para los objetos disponibles. En contextos donde los recursos materiales y tecnológicos son escasos para parte de la población, una gambiarra estético-tecnológica se reapropia creativamente de los medios y tecnologías y adquiere el potencial de táctica política al afirmarse como una alternativa para los escasos recursos" (Gontijo, 2014, p. 58).
} 
campo artístico anticipando las siguientes esculturas Hidrocinéticas - resultaron trabajos fundamentales para la historia de las poéticas electrónicas. Perpetuando el carácter visionario que recorre toda su producción, en Ciudad Hidroespacial el artista imaginó una urbe del futuro suspendida a más de mil metros sobre el nivel del mar, compuesta por hábitats que se acoplarían en función de las necesidades de sus habitantes. La ciudad contaría también con sitios dedicados a funciones diversas, como lugares para tener ganas y alargar la vida. En el Manifiesto firmado en 1971, Kosice explica que en la nueva ciudad se tomaría el agua de las nubes y se la descompondría por electrólisis, de manera que el oxígeno permitiría respirar, mientras que el hidrógeno sería procesado por una máquina de fisión nuclear que generaría la energía requerida. Con tono irónico, el Manifiesto ridiculizaba a todo aquel que considerara que la Ciudad Hidroespacial daba fe de un idealismo utópico:

Probablemente aparecerán otros condicionamientos pero en la ciudad hidroespacial nos proponemos destruir la angustia y las enfermedades, revalorizar el amor, los recreos de la inteligencia, el humor, el esparcimiento lúdico, los deportes, los júbilos indefinidos, las posibilidades mentales hasta ahora no exploradas, la abolición de los límites geográficos y del pensamiento. ¿Idealismo utópico? En absoluto. Los que no creen en su factibilidad es porque siguen aferrados a la caverna, a las guerras y diluvios. Por lo tanto disolver el arte en la vivienda y en la vida misma es preanunciar síntesis e integración (Kosice, 1971, s. p.).

En una descripción poética y rigurosa, María Gainza definió al proyecto como una "ciencia-ficción plástica" que une las ideas de Kosice con las maravillas imaginadas por Luciano Samosata en el siglo II, o por Ludovico Ariosto, catorce siglos más tarde: "Kosice comparte con ellos la creencia en otros muchos mundos habitables, la conquista del espacio en busca de un futuro posible" (Gainza, 2011, p. 209). Es sabido que la NASA consideró que Ciudad Hidroespacial podía ser factible, pero los costos serían extremadamente elevados. Sin dudas, la ciudad soñada por Kosice fue un proyecto precursor del arte espacial (space art) impulsado en los años ochenta, a partir de los vuelos orbitales. Para Ladislao Pablo Györi (2011, p. 38), los últimos comentarios del artista sobre la digitalización animada de los hábitats hidroespaciales darían la pauta de que en su propuesta subyacía una alternativa revolucionaria de concretar estas arquitecturas en un espacio virtual. Más aun, Györi detectó ciertas motivaciones ambientales al ponderar que Kosice solía subrayar que las rutas de navegación permitirían mantenerse arriba de la superficie terrestre y apartada de las órbitas en torno a la atmósfera. En este sentido, Ciudad Hidroespacial constituyó un verdadero aporte multidisciplinario a los intercambios entre el arte, la ciencia y la tecnología en la Argentina. 


\section{Neurosis identitaria: civilización mecanizada o barbarie artesanal}

La fe en el futuro no se manifestó de manera ecuánime en los imaginarios argentinos forjados desde comienzos del siglo XX. El cosmopolitismo de los sectores conservadores (Wechsler, 2010) coexistía con cierto desdeño hacia el proceso de modernización urbana. Este último fue encarnado por los artistas e intelectuales que añoraban el pasado perdido y defendían una utopía centrada en el escenario rural. Si Manuel Gálvez, Leopoldo Lugones y Ricardo Rojas expresaban desde distintas perspectivas un nacionalismo cultural melancólico en torno al Centenario de la Revolución de Mayo, una década más tarde Ricardo Güiraldes proclamaba un ruralismo utópico (Sarlo, 2007, p. 43), a la vez que Jorge Luis Borges impulsaba un criollismo urbano de vanguardia, afín a la propuesta estética y conceptual de Xul Solar, entrelazando tradiciones rioplatenses y corrientes europeas como el ultraísmo. La "argentinidad" ya no radicaba en la figura del gaucho y el ambiente del campo, sino en la construcción de personajes suburbanos. A diferencia de la obra plástica de Xul Solar, atraída por las máquinas y las ciudades fantásticas tecnologizadas, y lejos también de los paisajes urbanos futuristas descritos por Arlt como si fueran escenas de una película de Fritz Lang o Friedrich Murnau, Borges aún enunciaba la nostalgia hacia la ciudad criolla en vías de desaparición (Sarlo, 1995). Paralelamente, la izquierda nucleada en torno a la editorial Claridad, representada en el campo de las artes plásticas por los Artistas del Pueblo -José Arato, Adolfo Bellocq, Guillermo Facio Hébecquer, Agustín Riganelli y Abraham Vigo-, rechazó la tendencia del Grupo de Florida, a la cual calificaron como extranjerizante y cosmopolita. Optaron, en cambio, por plasmar la imagen de la vida del proletariado en aguafuertes, xilografías y litografías realistas que se valían de técnicas de reproducción sencillas para lograr su amplia difusión.

De todos modos, es conveniente evitar las frecuentes aseveraciones radicales que se agotan en el antagonismo tecnofilia martinfierrista/tecnofobia boediana. En la revista Martín Fierro y el Grupo de Florida, la técnica aparecía sobre todo como símbolo de lo nuevo, mientras que para la revista Claridad y los artistas de Boedo la máquina era el ícono de la explotación de la clase trabajadora; hubo, asimismo, zonas intermedias dadas por la concurrente seducción y rechazo hacia la técnica. Así lo testimonia la obra de algunos artistas que participaron simultáneamente de ambas publicaciones (García Cedro, 2011). Con todo, Wechsler (2010, p. 311) argumentó que los distintos actores fueron elaborando definiciones diferentes de lo nacional a partir de las percepciones sobre su realidad contemporánea: algunos traducían la pregunta identitaria en paisajes campestres y retratos de los personajes 
locales, otros mostraban la "cara sucia de la modernización" mediante un arte social que aspiraba a la liberación de los trabajadores oprimidos, y un tercer grupo apostaba al desarrollo de nuevos lenguajes que afianzaran un verdadero arte de vanguardia.

Lo cierto es que los idearios que asocian la máquina con el ámbito de la ciudad, por oposición al contexto rural ajeno a los avances de la técnica, hunden sus raíces en las tensiones decimonónicas entre "civilización" y "barbarie". Estas tensiones no fueron privativas del ámbito argentino, sino que se inscriben en la "neurosis identitaria" que, según la hipótesis de Mosquera (2010), ha expresado sus síntomas en el terreno de las artes plásticas, jugando de rebote a través de la apropiación de tendencias hegemónicas provenientes del Norte. En el marco del proyecto de investigación “Arte Contemporáneo del Ecuador” (Centro Ecuatoriano de Arte Contemporáneo), Mosquera sugirió que la pregunta latinoamericana por el "quiénes somos" había emergido de una serie de causas específicas propias de la historia de la región, como los múltiples componentes de su etnogénesis, los complejos procesos de acriollamiento e hibridación, la presencia de grandes grupos indígenas no integrados y el enorme flujo migratorio mantenido durante todo el siglo XX (Mosquera, 2010, p. 124). Por ejemplo, cuando en los años cuarenta José Medeiros participó de la Expedición RoncadorXingú, en Mato Grosso, impulsada por la presidencia de Getúlio Vargas, con el objetivo de adentrarse en el territorio central de Brasil, el artista tomó diversas fotografías que retrataban a los grupos indígenas de la zona. En una de ellas, titulada $O$ contato com os Xavantes, cinco indios pertenecientes a esta etnia amerindia empujaban desnudos una de las alas de una avioneta. Una sexta persona se asomaba en primer plano parcialmente, cubierta por la hélice. En otra imagen, un habitante yawalapiti, fotografiado de atrás, toma con su mano derecha una de las ruedas de la nave y apoya la izquierda sobre su parte delantera. Ambas fotografías resumen las antinomias tecnología/naturaleza y pasado/futuro, al mismo tiempo que recuerdan la figura del "bárbaro tecnizado", 11 referido por Oswald de Andrade en el Manifiesto Antropófago de 1928. Mediante la operación antropofágica implícita en la deglución de lenguajes artísticos extranjeros, en pos de la consolidación de un arte local, el bárbaro tecnizado expresa la posibilidad de apropiación del patrimonio cultural de los países centrales, incluso sus conocimientos y herramientas técnicas. Despojándola de su aspecto

\footnotetext{
${ }^{11}$ La noción de "bárbaro tecnizado", citada por Oswald de Andrade en el "Manifiesto Antropófago", fue propuesta por Hermann Graf Keyserling, filósofo y viajero alemán que recorrió Sudamérica en la década del veinte. Atravesado por ideales aristocráticos, clichés orientalistas y concepciones románticas, para Keyserling el bárbaro tecnizado era el resultado de la potencia destructiva de la técnica y el tiempo avasallador del progreso, en lugar de un símbolo de redención del mundo occidental en decadencia, tal como lo veía Andrade (Faria, 2013, p. 912).
} 
alienador, la Antropofagia contribuiría con la humanización de la técnica y la liberación de su potencial creativo (Nitschack, 2016).

La dicotomía entre civilización y barbarie marcó tajantemente los idearios argentinos. Aquella utopía encarnada por la consolidación de una nación moderna, forjada hacia fines del siglo XIX por la Generación del 80 y continuada durante la centuria siguiente, concibió a la máquina como “emblema de lo civilizado" (Cortés-Rocca, 2011, p. 14). De esa forma tendió a configurar una esfera tecnológica en tanto dominio universal, lo cual evitó problematizar los significados locales de los medios, instrumentos y herramientas comprometidos. Si la ciudad era concebida como el espacio civilizado que albergaba los desarrollos de la tecnología, el campo no era más que un territorio atrasado y vacío - un "desierto"- que había que ocupar. Según Paola Cortés-Rocca (2011, p. 128), quien se dedicó a estudiar las transformaciones culturales producidas por el surgimiento de la fotografía hacia fines del siglo XIX, la detentación de la máquina precedía al propio acto de conquista. Dicha posesión constituía el fundamento que desencadenó toda la operatoria: la civilización se autoconcedía el derecho de domesticación de la barbarie porque ostentaba la técnica que certificaba su carácter civilizado.

\section{Conclusiones}

A lo largo del artículo hemos rastreado las ideas, comportamientos, actitudes y conceptos que modularon los idearios de modernización latinoamericanos, muchos de ellos asociados a los intercambios entre el arte, la ciencia y la tecnología desde comienzos del siglo pasado. Las nociones de cultura de mezcla, neurosis identitaria, glorificación tecnológica, utopía e invención permiten hilvanar las diferentes concepciones poéticas, políticas y tecnocientíficas que poco a poco fueron gestándose en la escena local. Aquellas tendieron a pivotar entre las constantes influencias extranjeras y la insistencia de componentes vernáculos. En los imaginarios latinoamericanos, la exaltación de la máquina adoptó rasgos específicos a través de la inventiva tecnopoética y las reformulaciones de las utopías europeas en función de las realidades políticas, socio-económicas y culturales de nuestra región.

Por otra parte, el análisis de la glorificación tecnológica en las obras de vanguardia, junto con los conceptos de utopía e invención, posibilitaron una lectura horizontal de la historia a partir de puentes entre las obras de las primeras vanguardias y las emergencias del arte contemporáneo. En futuras investigaciones será preciso indagar el modo en que esta fascinación tecnológica se encuentra emparentada con el "proceso de espectacularización del 
arte contemporáneo", clasificado por Terry Smith (2012) como una de las tres corrientes características de los constantes vaivenes de la escena artística de nuestros tiempos; cada una motivada por una visión del arte diferente, atraída por formas y temáticas específicas, y asociada a otro sistema de difusión para sus prácticas. En las tácticas de impacto implementadas por esta tendencia replicarían las estrategias de choque de los movimientos de vanguardia. El espectacularismo recupera, así, el ímpetu experimental vanguardista (Smith, 2012), en este caso se restablece el optimismo tecnológico moderno y el efecto de shock producido por lo nuevo. Un relato histórico de estas características conduciría a pensar en términos de emergencias antes que de un origen único y estático, en discontinuidades, accidentes y desviaciones que sustituyan la concepción de historia lineal heredada de la Modernidad, y en constelaciones de escenas en lugar de obras y acontecimientos aislados; un desafío imperioso a la hora de ponderar el problema de la contemporaneidad y su relación con el ámbito artístico.

\section{Referencias bibliográficas}

AAVV. (1946). Manifiesto Invencionista. Revista Arte Concreto Invención, (1), 8.

Alonso, Rodrigo. (2009). El futuro ya no es lo que era: imaginarios de futuro en Argentina 1910-2010. Buenos Aires: Fundación OSDE.

Alonso, Rodrigo. (2015). Elogio de la Low-Tech: historia y estética de las artes electrónicas en América Latina. Buenos Aires: Luna Editores.

Altamirano, Carlos. (1990). Lo imaginario como campo del análisis histórico y social. Revista Punto de Vista, 38, 11-14.

Arden Quin, Carmelo. (1944). Son las condiciones materiales de la sociedad, las que condicionan las superestructuras ideológicas. Arturo: revista de artes abstractas, $1, \mathrm{~s}$. p.

Baczko, Bronislaw. (1991). Los imaginarios sociales: Memorias y Esperanzas Colectivas [1984]. Buenos Aires: Nueva Visión.

Bayley, Edgar. (1946). Sobre invención poética. Recuperado de http://cvaa.com.ar/02dossiers/concretos/05_docs_07.php

Brea, José Luis. (2002). La era postmedia. Acción comunicativa, práctica (post)artísticas y dispositivos neomediales. Salamanca: Consorcio Salamanca. 
Bürger, Peter. (2009). Teoría de la Vanguardia. Buenos Aires: Las Cuarenta.

Canalis, Ianina. (2010). El fotoliptófono y sus páginas sonoras. Sistemas antiguos de grabación sonora. Recuperado de http://fotoliptofono.blogspot.com.ar/2010/

Canalis, Ianina y Petrosino, Jorge. (2014). ¿Cuánta música cabe en una página de periódico? Sonido impreso en papel a principios del siglo XX. Questión. Revista Especializada en Periodismo y Comunicación, 1(42), 260-284.

Castoriadis, Cornelius. (1975). La institución imaginaria de la sociedad: Marxismo y teoría revolucionaria. Barcelona: Tusquets Editores.

Castoriadis, Cornelius. (2004). Técnica. Artefacto. Pensamientos sobre la técnica, 5, 50-66.

Cortés-Rocca, Paula. (2011). El tiempo de la máquina: retratos, paisajes y otras imágenes de la Nación. Buenos Aires: Colihue.

De Micheli, Mario. (1979). Las vanguardias artísticas del siglo XX. Madrid: Alianza Forma.

Faria, Daniel. (2013). As meditações americanas de Keyserling: um cosmopolitismo nas incertezas do tempo. Varia Historia, 29(51), 905-923.

Gabo, Naum; Pevsner, Antoine. (1979). Manifiesto Constructivista. En Mario De Micheli (Ed.), Las vanguardias artísticas del siglo XX (pp. 325-328). Madrid: Alianza Forma.

Gainza, María. (2011). Textos elegidos 2003-2010. Buenos Aires: Capital intelectual.

García, María Amalia. (2011). El arte abstracto. Intercambios culturales entre Argentina y Brasil. Buenos Aires: Siglo XXI.

García Cedro, Gabriela. (2011). Máquinas y maquinarias de la vanguardia porteña. En Claudia Kozak (Ed.), Poéticas/políticas tecnológicas en Argentina 1910-2010 (pp. 1938). Paraná: Editorial Fundación La Hendija.

Gontijo, Juliana. (2014). Distopias Tecnológicas. Río de Janeiro: Circuito.

Gontijo, Juliana. (2016). El artista como inventor: mutaciones tecnopoéticas (Tesis doctoral). Universidad de Buenos Aires.

Gradowczyk, Mario. (2006). Arte abstracto. Cruzando líneas desde el Sur. Buenos Aires: EDUNTREF.

Gutman, Margarita. (2011). Buenos Aires: el poder de la anticipación, 1900-1920. Recuperado de http://www.scielo.org.ar/scielo.php?script=sci_arttext\&pid=S236220242011000100006

Györi, Ladislao Pablo. (2011). Kosice y el arte tecnológico. Buenos Aires: Aero.

Huidobro, Vicente. (1976). "Futurismo y Maquinismo" [1925] en Obras Completas. Santiago de Chile: Editorial Andrés Bello. 
Huyssen, Andreas. (2006). Después de la gran división: modernismo, cultura de masas, posmodernismo [1986]. Buenos Aires: Adriana Hidalgo.

Kosice, Gyula. (1947) "Manifiesto Madí”. Recuperado de http://cvaa.com.ar/02dossiers/concretos/05_docs_10.php

Kosice, Gyula. (1971). "Manifiesto La Ciudad Hidroespacial”. Recuperado de http://kosice.com.ar/otros-recursos/los-textos/de-kosice/manifiesto-la-ciudadhidroespacial/

Larios, Shadey. (2011). Muestrario Lunar. En Andrés Padilla Domene e Iván Puig (Eds.), SEFT-1. Sonda de Exploración Ferroviaria Tripulada (pp. 108-139). Ciudad de México: Conaculta.

Lodder, Christina. (1988). El constructivismo ruso. Madrid: Alianza Forma.

Maples, Manuel. (1921). “Actual n.1, Hoja de Vanguardia, Comprimida Estridentista del poeta Manuel Maple Arce”. Recuperado de http://artespoeticas.librodenotas.com/artes/1571/manifiesto-estridentista-1921

Moholy-Nagy, László y Kemeny, Alfred. (2009). "Sistema Constructivo-Dinámico-Fuerza". En Francisco Calvo Serraller, Ángel González García y Simón Marchan Fiz (Eds.), Escritos de Vanguardia 1900/1945 (p. 378). Madrid: Akal.

Montero, Valentina. (2015). Arte de los medios y transformaciones sociales durante la transición en Chile 1990-2014 (Tesis doctoral). Universidad de Barcelona.

Mosquera, Gerardo. (2010). Caminar con el diablo: textos sobre arte, internacionalismo y culturas. Madrid: Exit.

Nitschack, Horst. (2016). “Antropofagia cultural y tecnología”. Recuperado de https://scielo.conicyt.cl/scielo.php?script=sci_arttext\&pid=S071823762016000200010.

Oud, Jacobus Johannes Pieter. (1918). "Art and Machine”. Recuperado de https://modernistarchitecture.wordpress.com/2010/10/17/j-j-p-oud's-“art-andmachine"-1918/

Padilla Domene, Andrés y Puig, Iván. (2011). SEFT-1. Sonda de Exploración Ferroviaria Tripulada. Ciudad de México: Conaculta.

Pardo, María Cecilia Lourdes. (2010). La ciudad estridentista. Representaciones subjetivas y urbanas de una modernidad por venir. Actas del IV Congreso Internacional de Letras de la Universidad de Buenos Aires, 1689-1693. 
Prieto González, José Manuel. (2011). "El estridentismo mexicano y su construcción de la ciudad moderna a través de la poesía y la pintura". Recuperado de http://www.ub.edu/geocrit/sn/sn-398.html

Puig, Iván y Padilla Domene, Andrés. (2006-2011). SEFT-1. Sonda de Exploración Ferroviaria Tripulada. Ciudad de México: ivanpuig.net. Recuperado de https://www.ivanpuig.net/seft.html

Rothfuss, Rod. (1944). El MARCO: un problema de la plástica actual. Recuperado de http://cvaa.com.ar/02dossiers/concretos/05_docs_04.php

Rossi, Cristina. (2016). Redes latinoamericanas de arte constructivo. Cuadernos del Centro de Estudios de Arte y Comunicación, 60, 103-125.

Sarlo, Beatriz. (1992). La imaginación técnica: sueños modernos de la cultura argentina. Buenos Aires: Nueva Visión.

Sarlo, Beatriz. (1995). Borges, un escritor en las orillas. Buenos Aires: Ariel.

Sarlo, Beatriz. (2007). Una modernidad periférica: Buenos Aires 1920 y 1930. Buenos Aires: Nueva Visión.

Scharf, Aaron. (2006). "Constructivism”. En Nikos Stangos (Ed.), Concepts of Modern Art: From Fauvism to Postmodernism (pp. 160-168). Londres: Thames \& Hudson.

Simondon, Gilbert. (2013). Imaginación e invención. Buenos Aires: Editorial Cactus.

Smith, Terry. (2012). ¿Qué es el arte contemporáneo? Buenos Aires: Siglo XXI.

Smithson, Robert. (1967). “The Monuments of Passaic”. Recuperado de http://opencourses.uoa.gr/modules/document/file.php/ENL9/Instructional\%20Package /Texts//Readings/Week\%208\%3A\%20Earthworks\%2C\%20Video\%2C\%20Performan ce/smithson-2.pdf

Speranza, Graciela. (2017). Cronografías: Arte y ficciones de un tiempo sin tiempo. Barcelona: Anagrama.

Wechsler, Diana. (2010). “Impacto y matices de una modernidad en los márgenes”. En José Emilio Burucúa (Ed.), Nueva historia argentina. Volumen I: Arte, Sociedad y Política (pp. 269-312). Buenos Aires: Sudamericana.

Wick, Rainer. (2007). La pedagogía de la Bauhaus. Madrid: Alianza Forma.

Yeregui, Mariela. (2013). Derivas y paisajes. En los confines de territorio. Blanco sobre blanco, (5), 33-60. 